\title{
Volvulus as a complication of chronic intestinal pseudo-obstruction syndrome
}

\author{
Carlijn T. de Betue $\cdot$ Doeke Boersma . \\ Matthijs W. Oomen • Marc A. Benninga • \\ Justin R. de Jong
}

Received: 28 May 2011 / Accepted: 4 August 2011 /Published online: 23 September 2011

(C) The Author(s) 2011. This article is published with open access at Springerlink.com

\begin{abstract}
Chronic intestinal pseudo-obstruction syndrome (CIPS) is a severe motility disorder of the gastrointestinal tract that presents with continuous or recurrent symptoms and signs of intestinal obstruction without evidence of a structural lesion occluding the intestinal lumen. Mechanical obstruction might occur in these patients as well but is typically difficult to distinguish from an exacerbation of CIPS. We report two pediatric cases in which mechanical obstruction by volvulus mimicked an exacerbation of CIPS, requiring surgical intervention. Conclusion: Awareness of the possibility of true mechanical obstruction in CIPS patients during an exacerbation episode is needed, as this is a severe condition and usually requires surgical intervention.
\end{abstract}

C. T. de Betue $\cdot$ D. Boersma $\cdot$ M. W. Oomen $\cdot$ J. R. de Jong $(\triangle)$

Department of Pediatric Surgery,

Emma Children's Hospital/Academic Medical Center,

Meibergdreef 9,

1105 AZ Amsterdam, The Netherlands

e-mail: j.r.dejong@amc.uva.nl

C. T. de Betue

Department of Pediatric Surgery and Intensive Care,

Erasmus MC - Sophia Children's Hospital,

University Medical Center,

Dr. Molewaterplein 60,

3015 GJ Rotterdam, The Netherlands

\section{Boersma}

Department of Surgery, St. Antonius Hospital,

Koekoekslaan 1,

3435 CM Nieuwegein, The Netherlands

\section{A. Benninga}

Department of Pediatric Gastroenterology and Nutrition,

Emma Children's Hospital/Academic Medical Center,

Meibergdreef 9 ,

1105 AZ Amsterdam, The Netherlands
Keywords Children · Chronic intestinal pseudo-obstruction . Volvulus · Pediatric surgery · Mechanical obstruction

\section{Introduction}

Chronic intestinal pseudo-obstruction syndrome (CIPS) is a rare, severe gastrointestinal motility disorder, characterized by recurrent or continuous signs and symptoms suggesting mechanical bowel obstruction in the absence of a lesion that occludes the intestinal lumen [3, 14, 15]. Generally, no curative treatment is available and morbidity and mortality are high. Although the absence of mechanical obstruction is imperative for the initial diagnosis of CIPS, true mechanical obstruction is a possible complication. In CIPS patients, this condition is particularly hard to recognize because the presentation is indistinguishable from common CIPS symptoms. Here, we report two cases of mechanical obstruction caused by volvulus in children with CIPS.

\section{Case 1}

An 8-year-old boy, diagnosed at 3 years of age with hypoperistaltic dysmotility of intestines and bladder as a variant of CIPS, was admitted to our tertiary pediatric hospital. Extensive histopathological examination showed no underlying disease. In the past, he had undergone two operations of the bladder (size reduction and valve resection) and biopsies of the bowel. Neurological symptoms were absent, and no other signs of involvement of mitochondrial disorders were observed.

At admission, the boy presented with abdominal pain, abdominal distension, increased gastric retention, and decreased defecation frequency. Initially, these symptoms 
were interpreted as an exacerbation of CIPS and conservative treatment with gastric decompression by nasogastric tube was started. During hospitalization, the boy clinically deteriorated with increasing gastric retention, abdominal distension, and severe crampy abdominal pain. There was no spontaneous defecation, even after colonic irrigation. At physical examination, the abdomen was painful and progressively distended. A plain abdominal radiograph showed extremely dilated bowel loops. The ineffectiveness of the conservative treatment and meanwhile clinical deterioration were suggestive for mechanical obstruction. Therefore, we proceeded to surgical intervention.

At laparotomy, an extremely dilated bowel loop came into view, with a diameter of approximately $20 \mathrm{~cm}$ (Fig. 1). It appeared to involve the majority of the transverse colon, which was rotated three times around itself. Possibly, this was a result of torsion of the dilated and fluid-filled transverse colon. After derotation of the volvulus, a suction device was placed rectally for decompression and $3 \mathrm{~L}$ of intraintestinal fluid could be drained. During the postoperative course, the patient recovered quickly.

\section{Case 2}

A 2-year-old boy, with CIPS and a high-output ileostomy for which no specific etiologic factor had been found, was admitted to our hospital. CIPS had been diagnosed in the first few months following premature birth, and the patient had since been dependent of total parenteral nutrition (TPN). A split ileostomy had previously been constituted for

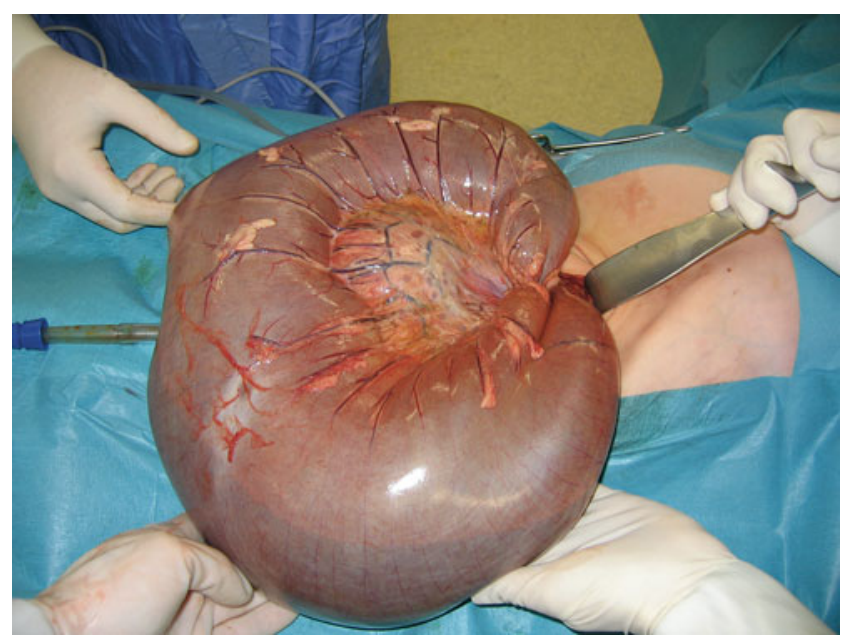

Fig. 1 Volvulus in an 8-year-old boy with chronic intestinal pseudoobstruction syndrome. An 8-year-old boy with chronic intestinal pseudo-obstruction syndrome presented with deteriorating symptoms of mechanical obstruction without improvement on conservative treatment. At laparotomy, an extremely dilated transverse colon with a diameter of about $20 \mathrm{~cm}$ was found as a result of transverse colonic volvulus bowel decompression. Mitochondrial neurogastrointestinal encephalomyopathy (MNGIE) syndrome had been considered as underlying disorder. However, ophthalmoplegia, polyneuropathy, and other neurological symptoms were absent; urine thymidine was normal, and on MRI, no leukoencephalopathy was seen. Because MNGIE syndrome was therefore deemed unlikely, MNGIE gene analysis was not performed.

At this time, he presented at the emergency department with a 3-day course of abdominal pain, progressive abdominal distension, fluctuating febrile temperature, coughing, and malaise. The symptoms were first thought to be part of an exacerbation of CIPS. However, the ileostomy production had decreased over the past few days, which was in contradiction with the usual output of $3 \mathrm{~L} /$ day. At physical examination, an ill child was seen with a need for oxygen support and a painful and severely distended abdomen. Plain abdominal radiography showed strongly dilated bowel loops. Suspicion of a mechanical obstruction arose, and gastric decompression by nasogastric tube was not awaited because of the severity of illness of the patient. At laparotomy, dilated fluid-filled bowel loops were seen, which were caused by a volvulus of the small intestine. The cause seemed to be torsion of the fluid-filled loops of decompensated bowel. The volvulus was derotated, and the intestine was drained with a suction device via the ileostomy. The postoperative course was uneventful.

\section{Discussion}

CIPS is characterized by impaired propulsion of contents of the gastrointestinal tract, which results in the clinical picture of intestinal obstruction. Symptoms at first presentation in CIPS patients are abdominal distension (98\%), vomiting (91\%), constipation (77\%), failure to thrive (62\%), abdominal pain (58\%), and diarrhea (31\%) [7]. Radiographic evidence of dilated bowel with air-fluid levels is obligatory to diagnose CIPS [14, 15]. CIPS is either a primary condition or secondary to a wide range of pathological conditions such as systemic diseases with gastrointestinal involvement, electrolyte disorders, toxic, viral, parasitic, or immunemediated causes. Primary CIPS can be congenital or acquired, and underlying pathohistological abnormalities are classified as neuropathy, mesenchymopathy, or myopathy $[6,15]$. These entities respectively refer to affected (intrinsic and extrinsic) gastrointestinal nerve pathways, interstitial cells of Cajal, and smooth muscle cells (Table 1). All etiologic factors lead to dysmotility of the gastrointestinal tract. Extent of involvement of the tract varies from merely a small region to the entire tract including esophagus and stomach. In the second case, the affected part of the gastrointestinal tract was extended from stomach to colon. 
Table 1 Pathogenesis of chronic intestinal pseudo-obstruction syndrome $[6,7,10,11]$

\begin{tabular}{|c|c|c|c|}
\hline Entity & Affected cells & Pathogenesis & Underlying disease \\
\hline \multirow[t]{11}{*}{ Neuropathy } & \multirow[t]{11}{*}{$\begin{array}{l}\text { Enteric, sympathetic, or } \\
\text { parasympathetic neurons }\end{array}$} & \multirow{8}{*}{$\begin{array}{l}\text { Inflammation of myenteric plexus, } \\
\text { submucous plexus, or axons (infiltration } \\
\text { of lymphocytes, humoral response with } \\
\text { antineuronal bodies) }\end{array}$} & $\begin{array}{l}\text { Infection, e.g., Chagas disease, CMV, or } \\
\text { EBV infection }\end{array}$ \\
\hline & & & $\begin{array}{l}\text { Neurological disease, e.g., } \\
\text { encephalomyeloneuropathy }\end{array}$ \\
\hline & & & Autoimmune, e.g., scleroderma \\
\hline & & & $\begin{array}{l}\text { Inflammatory diseases, e.g., inflammatory } \\
\text { bowel disease }\end{array}$ \\
\hline & & & $\begin{array}{l}\text { Paraneoplastic to, e.g., small cell carcinoma, } \\
\text { carcinoid, neuroblastoma, thymoma }\end{array}$ \\
\hline & & & Endocrine, e.g., hypothyroidism \\
\hline & & & Other, e.g., amyloidosis \\
\hline & & & Idiopathic \\
\hline & & \multirow{2}{*}{$\begin{array}{l}\text { Degeneration of neurons (reduction in } \\
\text { neurons, structural abnormalities, } \\
\text { proliferation of glial cells) }\end{array}$} & $\begin{array}{l}\text { Endogenous and exogenous stimuli leading } \\
\text { to damage and loss of enteric neurons: }\end{array}$ \\
\hline & & & $\begin{array}{l}\text { e.g., altered calcium signaling, } \\
\text { mitochondrial disorders, free radicals, and } \\
\text { reduced gene expression of B cell } \\
\text { lymphoma } 2 \text { gene leading to neuronal } \\
\text { apoptosis }\end{array}$ \\
\hline & & Hyperganglionosis & $\begin{array}{l}\text { E.g. neuronal intestinal dysplasia, and } \\
\text { MEN2B }\end{array}$ \\
\hline Mesenchymopathy & ICC & $\begin{array}{l}\text { Altered ICC network, i.e., decreased or } \\
\text { increased presence of ICC and structural } \\
\text { abnormalities }\end{array}$ & \\
\hline \multirow[t]{6}{*}{ Myopathy } & \multirow{6}{*}{$\begin{array}{l}\text { Smooth muscle cells of the } \\
\text { circular and longitudinal } \\
\text { muscle layers of the } \\
\text { intestinal wall }\end{array}$} & \multirow{6}{*}{$\begin{array}{l}\text { Abnormal architecture of muscle layers } \\
\text { (e.g., additional muscle layer), } \\
\text { degeneration (fibrosis, vacuolization, } \\
\text { inclusion bodies), and } \alpha \text {-actin } \\
\text { abnormalities/deficiency }\end{array}$} & Primary visceral myopathy \\
\hline & & & $\begin{array}{l}\text { Muscular dystrophy, e.g., Duchenne's } \\
\text { disease }\end{array}$ \\
\hline & & & Myotonic dystrophy \\
\hline & & & Mitochondrial disorders, e.g., MELAS \\
\hline & & & Autoimmune disorders \\
\hline & & & Other \\
\hline
\end{tabular}

$C M V$ cytomegalovirus; $E B V$ Epstein-Barr virus; $I C C$ interstitial cells of Cajal; $M E L A S$ mitochondrial myopathy, encephalopathy, lactic acidosis, stroke-like episodes; $M E N 2 B$ multiple endocrine neoplasia, type 2B

Extra-gastrointestinal manifestations may also be apparent in some forms of primary CIPS, for example, dysmotility of the urinary tract as in the first case. Other extra-gastrointestinal symptoms include neurological problems and skeletal and ocular weakness. These are usually the result of defects of the mitochondrial oxidative phosphorylation pathway. An example is MNGIE, which is a rare, autosomal recessive syndrome affecting thymidine phosphorylase activity [12]. Gastrointestinal manifestations, such as CIPS, are usually the first sign in this progressive disease $[12,16]$. Several other mitochondrial defects are related to the occurrence of CIPS. The frequency of mitochondrial disorders as cause of CIPS is however not known well; a recent report found underlying mitochondrial defects in one third of patients [2].

The management of CIPS depends on the underlying cause of pseudo-obstruction. In every case, optimal nutrition is an important aim, preferably via the enteral route. If enteral nutrition is not possible due to insufficient motility or enteral uptake, TPN is a necessity. Severely affected individuals may become chronically TPN dependent, but long-term TPN is related to high morbidity and mortality [7,9]. Pharmacological therapy, such as prokinetics, may help in controlling symptoms [3, 5]. A frequent complication of CIPS is bacterial overgrowth due to stasis of intestinal contents, causing malabsorption and in some cases sepsis. Intermittent antibiotic treatment is used to minimize the risk of bacterial overgrowth $[5,14]$.

Some cases require surgical interventions. Gastrostomies and enterostomies are constituted for intermittently venting dilated bowel and can be used for the administration of nutrition [8]. In localized disease, resection of the affected gastrointestinal tract can be a curative treatment. In patients with total gastrointestinal tract involvement and who are entirely TPN dependent, intestinal transplantation is the 
ultimate treatment modality to achieve a TPN-independent life [8]. Multiple surgical interventions are strongly discouraged, though. In retrospective studies, 50-60\% of CIPS patients were diagnosed via a laparotomy excluding mechanical obstruction [7,9]. Those patients presenting with an acute onset suggestive for mechanical obstruction had a high risk to undergo laparotomy. Because previous surgery is a risk factor for adhesions that might cause mechanical obstruction, a following obstructive episode is difficult to interpret. The decision for another, possibly unnecessary, intervention might be made on these grounds. Indeed in one of the retrospective studies, only few patients underwent single laparotomy [7]. In the other study, procedures performed during primary surgical intervention did not relieve symptoms in over $50 \%$ of patients [9]. Reconstituting continuity of the gastrointestinal tract in patients with an effective decompression ileostomy is discouraged since in diffuse disease, this may lead to new episodes of obstruction $[8$, 9]. Thus, it should be realized that surgical interventions are often unsuccessful in CIPS patients and that multiple interventions might enhance the risk for multiple obstructive episodes on the long term. Moreover, besides possibly generating adhesions that predispose to mechanical obstruction, surgical interventions elicit the risk of general surgical complications and may lead to postoperative paralytic ileus, which contributes to dysmotility.

Although mechanical obstruction is normally absent in CIPS patients, it can be a complication of CIPS, especially after multiple interventions. As illustrated by our two cases, adhesions are not the only cause of mechanical obstruction; volvulus due to torsion of fluidfilled bowel loops may occur as well. Stasis of intestinal contents is common in CIPS, and chronic dilatation leads to decompensation and elongation of the bowel, further impairing motility. When fluid and air accumulate in these decompensated loops, torsion caused by mechanical forces is possible. The condition has been described in some case reports. Osuka et al. described volvulus of the splenic flexure in patients with CIPS [13]. Another report summarized transverse colon volvulus in children with different underlying diseases causing elongation and distension of the bowel, e.g., irregular bowel function in mental retardation and chronic constipation [4]. Furthermore, Altaf et al. reported eight patients with colonic volvulus as a complication of CIPS or chronic intractable constipation [1].

Thus, mechanical obstruction by volvulus of decompensated bowel or strangulation due to adhesions should be part of the differential diagnosis in exacerbations of CIPS. Distinguishing an event of mechanical obstruction from the "normal" pseudo-obstructive episodes is difficult. As illustrated by our two cases, recognition of true mechanical obstruction is however important as it usually requires acute surgical intervention and is potentially life threatening when treatment is omitted. Awareness should be raised when little or no improvement is seen on standard treatment, such as bowel decompression, in exacerbations with abdominal pain and distension, vomiting, and decreased defecation. Signs that point more towards mechanical obstruction are extreme dilatation, signs of peritonism, and pain that is related to specific episodes of aggravating obstructive symptoms [8]. Furthermore, one should be cautious when abdominal distention at physical examination and bowel dilatation on plain radiographic examination are exceeding the usual proportions for the patient in question, such as in our cases. Although explorative laparotomies should still be highly discouraged in CIPS, sometimes the decision for surgical intervention has to be made if there is enough evidence of true mechanical obstruction. Contrast studies and CT scans are especially helpful to exclude an occluding lesion during obstructive periods. The use of these techniques before proceeding to surgical intervention is therefore recommended as well as initially attempting conservative treatment with bowel decompression by nasogastric suction.

In conclusion, these two cases illustrate that awareness of the possibility of true mechanical obstruction, as a complication of CIPS, is needed in CIPS patients without improvement of an exacerbation on conservative treatment. It is a severe, potentially life-threatening condition and usually requires surgical intervention.

Conflicts of interest All authors declare no conflict of interest.

Open Access This article is distributed under the terms of the Creative Commons Attribution Noncommercial License which permits any noncommercial use, distribution, and reproduction in any medium, provided the original author(s) and source are credited.

\section{References}

1. Altaf MA, Werlin SL, Sato TT, Rudolph CD, Sood MR (2009) Colonic volvulus in children with intestinal motility disorders. J Pediatr Gastroenterol Nutr 49:59-62

2. Amiot A, Tchikviladze M, Joly F, Slama A, Hatem DC, Jardel C, Messing B, Lombes A (2009) Frequency of mitochondrial defects in patients with chronic intestinal pseudo-obstruction. Gastroenterology 137:101-109

3. Antonucci A, Fronzoni L, Cogliandro L, Cogliandro RF, Caputo C, De Giorgio R, Palloti F, Barbara G, Corinaldesi R, Stranghellini V (2008) Chronic intestinal pseudo-obstruction. World J Gastroenterol 14:2953-2961

4. Asabe K, Ushijima H, Bepu R, Shirakusa T (2002) A case of transverse colon volvulus in a child and a review of the literature in Japan. J Pediatr Surg 37:1626-1628 
5. Connor FL, Di Lorenzo C (2006) Chronic intestinal pseudoobstruction: assessment and management. Gastroenterology 130: S29-S36

6. De Giorgio R, Sarnelli G, Corinaldesi R, Stanghellini V (2004) Advances in our understanding of the pathology of chronic intestinal pseudo-obstruction. Gut 53:1549-1552

7. Faure C, Goulet O, Ategbo S, Breton A, Tounian P, Ginies JL, Roquelaure B, Depres C, Scaillon M, Marage C, Paquot I, Hermier M, de Napoli S, Dabadie A, Huet F, Baudon JJ, Larchet M (1999) Chronic intestinal pseudoobstruction syndrome: clinical analysis, outcome, and prognosis in 105 children. French-speaking Group of Pediatric Gastroenterology. Dig Dis Sci 44:953-959

8. Goulet O, Sauvat F, Jan D (2005) Surgery for pediatric patients with chronic intestinal pseudo-obstruction syndrome. J Pediatr Gastroenterol Nutr 41(Suppl 1):S66-S68

9. Heneyke S, Smith VV, Spitz L, Milla PJ (1999) Chronic intestinal pseudo-obstruction: treatment and long term follow up of 44 patients. Arch Dis Child 81:21-27

10. Kapur RP (2001) Neuropathology of paediatric chronic intestinal pseudo-obstruction and related animal models. J Pathol 194:277-288

11. Lindberg G, Törnblom H, Iwarzon M, Nyberg B, Martin JE, Veress B (2009) Full-thickness biopsy findings in chronic intestinal pseudo-obstruction and enteric dysmotility. Gut 58:1084-1090
12. Nishino I, Spinazzola A, Papadimitriou A, Hammans S, Steiner I, Hahn CD, Connolly AM, Verloes A, Guimarães J, Maillard I, Hamano H, Donati MA, Semrad CE, Russell JA, Andreu AL, Hadjigeorgiou GM, Vu TH, Tadesse S, Nygaard TG, Nonaka I, Hirano I, Bonilla E, Rowland LP, DiMauro S, Hirano M (2000) Mitochondrial neurogastrointestinal encephalomyopathy: an autosomal recessive disorder due to thymidine phosphorylase mutations. Ann Neurol 47:792-800

13. Osuka A, Ikegami R, Watanabe Y (2006) Splenic flexure volvulus in a child with chronic idiopathic intestinal pseudo-obstruction syndrome. Pediatr Surg Int 22:833-835

14. Rudolph CD, Hyman PE, Altschuler SM, Christensen J, Colletti RB, Cucchiara S, Di Lorenzo C, Flores AF, Hillemeier AC, McCallum RW, Vanderhoof JA (1997) Diagnosis and treatment of chronic intestinal pseudo-obstruction in children: report of consensus workshop. J Pediatr Gastroenterol Nutr 24:102-112

15. Stanghellini V, Cogliandro RF, De Giorgio R, Barbara G, Cremon C, Antonucci A, Fronzoni L, Cogliandro L, Naponelli V, Serra M, Corinaldesi R (2010) Natural history of intestinal failure induced by chronic idiopathic intestinal pseudo-obstruction. Transplant Proc 42:15-18

16. Teitelbaum JE, Berde CB, Nurko S, Buonomo C, Perez-Atayde AR, Fox VL (2002) Diagnosis and management of MNGIE syndrome in children: case report and review of the literature. J Pediatr Gastroenterol Nutr 35:377-383 